\title{
LOS CLUSTERS DEL CONOCIMIENTO \\ UNA IMPORTANTE HERRAMIENTA PARA LA TRANSFORMACIÓN PRODUCTIVA
}

Mauricio Nieto Potes*

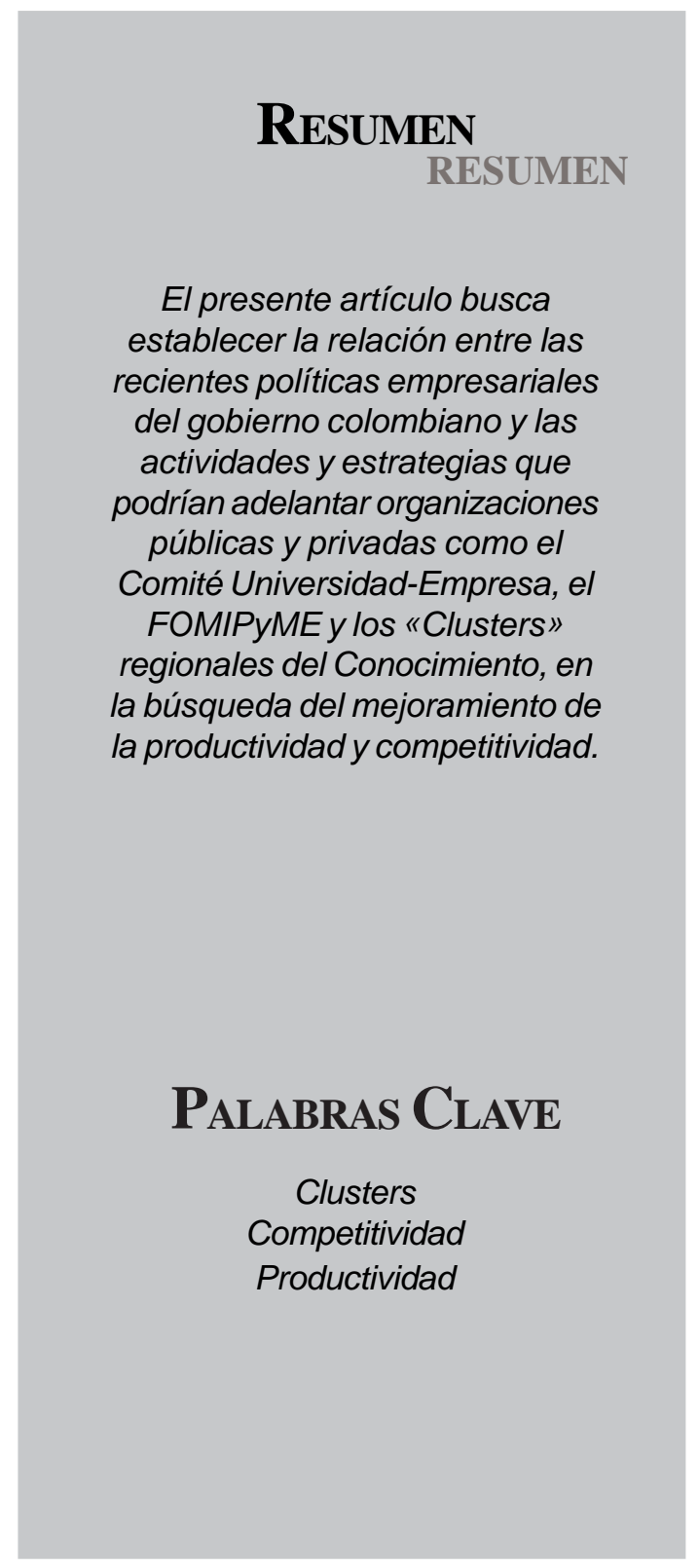

\section{INTRODUCCIÓN}

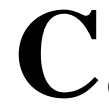

olombia está dando pasos muy importantes para aumentar la productividad y la competitividad de su economía y sus organizaciones. Un ambicioso proceso de transformación del aparato productivo se ha iniciado con la puesta en marcha de la política para el desarrollo empresarial cuyos lineamientos se presentan en el documento CONPES No.3484: «Política nacional para la transformación productiva y la promoción de las micro, pequeñas y medianas empresas: un esfuerzo públicoprivado". ${ }^{1}$ Este documento constituye la brújula para los programas de gobierno en cuanto al desarrollo empresarial durante los próximos años.

* Vicerrector de Investigación Universidad EAN, Economista Universidad Nacional, D.E.A. Universidad de Paris I-Sorbone, Miembro del equipo investigador de Gestión del Conocimiento Universidad EAN.

${ }^{1}$ El documento presentado al Consejo de Política Económica y Social -CONPES- (documento CONPES No. 3484) fue aprobado por el Presidente de la República con la participación de los Ministros de Estado, el 13 de agosto de 2007. Los planteamientos de este documento fueron elaborados por el Ministerio de Comercio, Industria y Turismo y por el Departamento Nacional de Planeación con la colaboración de un grupo de entidades públicas y privadas, entre las cuales estuvo la Universidad EAN. Las políticas que resume el documento fueron presentadas a los empresarios en septiembre de 2007, con ocasión del $54^{\circ}$ Congreso de ACOPI.

Este artículo fué entregado el 18 de septiembre de 2007 y su publicación aprobada por el Comité Editorial el 29 de noviemre de 2007 
De la política gubernamental se desprenden elementos que deben constituir los ejes centrales para el trabajo de organizaciones, entre ellos, el Comité Universidad-Empresa que está comenzando a operar en Bogotá. Igualmente, adoptando las orientaciones que propone esta política, entidades como el FOMIPyME, los gremios empresariales y las universidades pueden refinar sus programas de apoyo a la modernización de las empresas lo cual les permitirá tener cada vez un mayor impacto en el desarrollo económico.

La existencia de la Agenda Interna para la productividad y la competitividad, que recopiló en las diferentes regiones del país una amplia lista de proyectos puntuales, constituye un complemento importante de la política de transformación. Es claro, sin embargo, que ante la escasez de recursos será necesario establecer prioridades y apoyar principalmente aquellos proyectos regionales o nacionales que promuevan la conformación de asociaciones 0 «clusters» e incluyan procesos y productos innovadores que exijan procesos de asimilación, adaptación o creación de conocimiento.

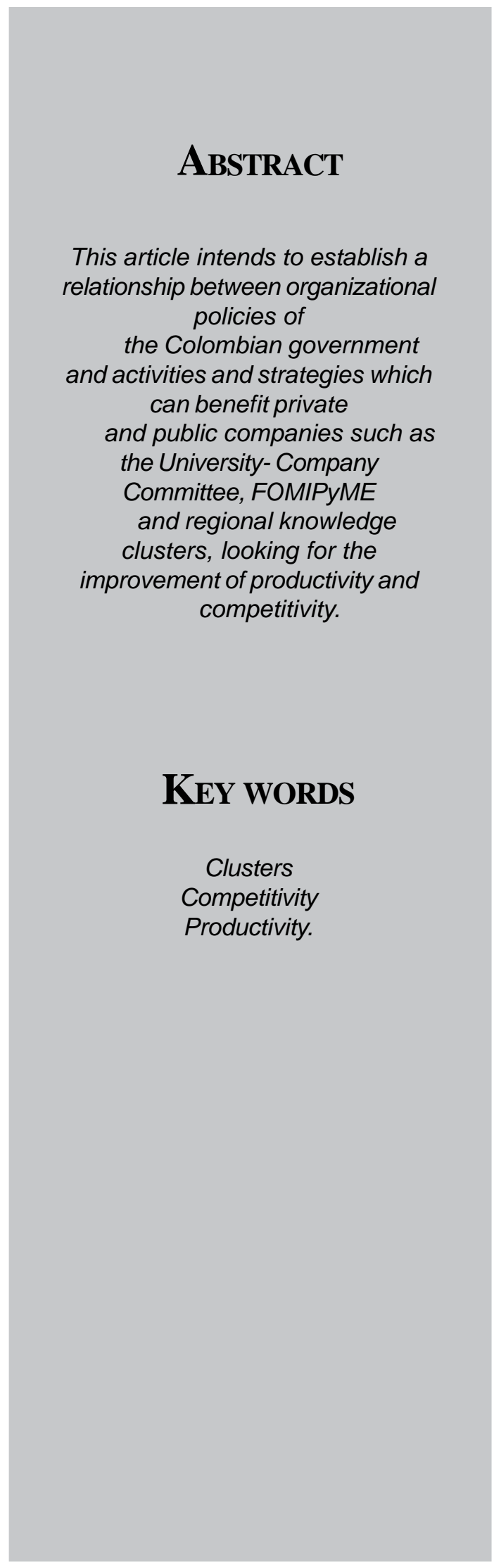




\section{COMPETITIVIDAD SISTÉMICA Y «CLUSTERS» DE CONOCIMIENTO. REQUISITO Y HERRAMIENTAS PARA LA TRANSFORMACIÓN PRODUCTIVA}

$\mathbf{E}$

la actualidad se entiende como un requisito básico para alcanzar el desarrollo económico y empresarial de un país como Colombia, lograr el alineamiento -desde una perspectiva de competitividad sistémica- de las políticas para adaptarse o modificar los entornos económicos con los programas específicos de modernización de las organizaciones. Este alineamiento de las políticas en los diferentes niveles, es una condición "sine qua non" para aumentar la competitividad y la productividad de las empresas y de la economía nacional.

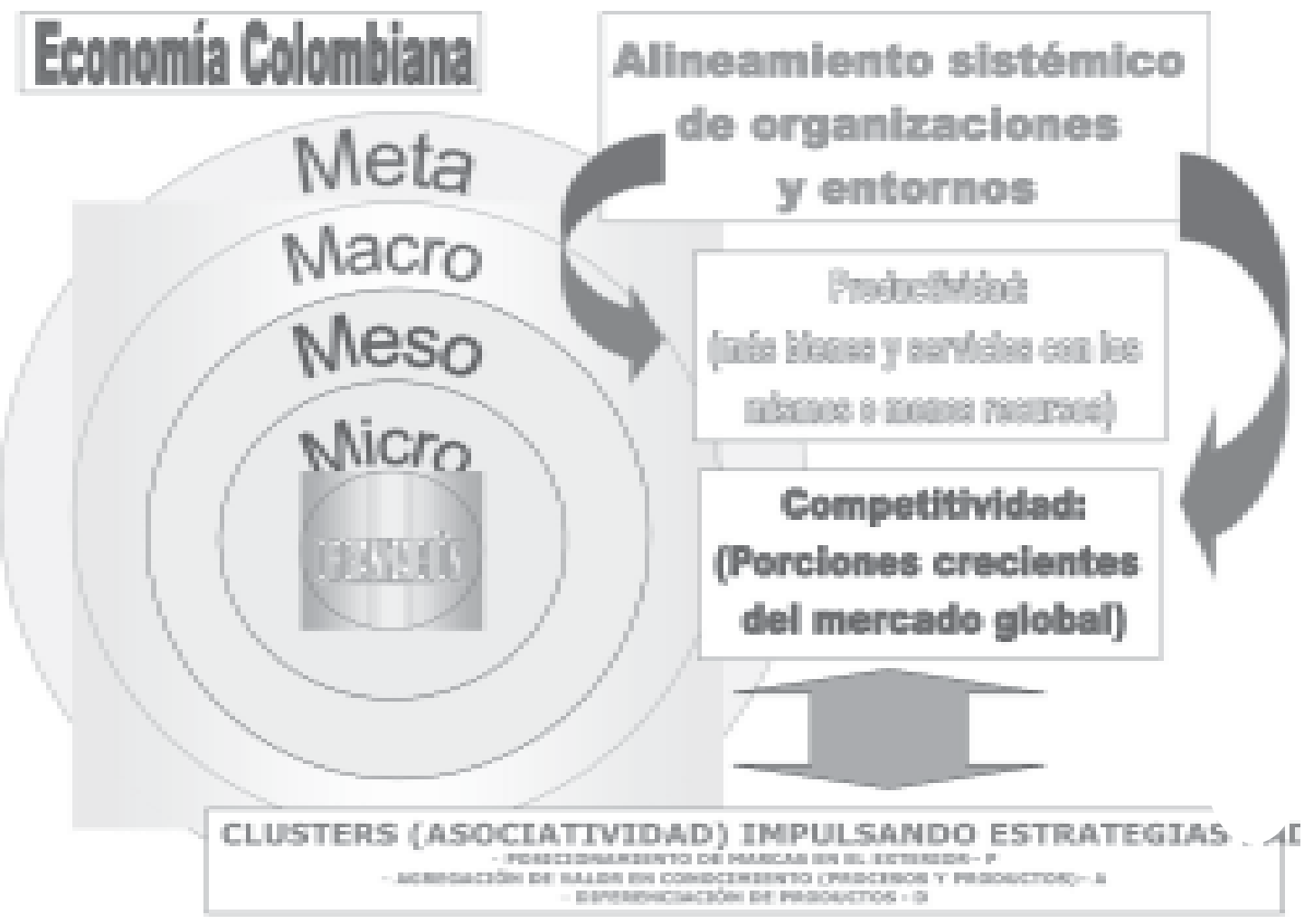

En el sentido de las políticas y de los proyectos puntuales necesarios para la transformación productiva y el desarrollo empresarial, se puede afirmar que ya existen muy buenas aproximaciones en los planteamientos de los documentos "Visión Colombia, segundo centenario: 2019", "CONPES No.3484" y "Agenda Interna de Competitividad". Es necesario ahora fortalecer los instrumentos operativos (o crear nuevos) que permitan concretar dichas políticas. Es allí donde el redireccionamiento que se está dando en el accionar de instituciones como Bancoldex y Proexport y en organismos como FOMIPyME, así como la creación de "Clusters" de Conocimiento, pueden constituir los espacios de coordinación que reúnan al gobierno, al empresariado y a la academia en proyectos concretos para la producción de 
conocimiento útil y para el impulso de estrategias del tipo PAD (Posicionamiento de marca, Agregación de valor en conocimiento y Diferenciación de producto), estrategia que se ilustrará más adelante.

Se trata, en síntesis, de poner en marcha las recomendaciones que han hecho para Colombia famosos economistas como R. Haussman (2007), J. Stiglitz (2007) y M. Porter (2007), quienes en 2007 coincidieron en afirmar que la profundización del proceso de desarrollo manufacturero haciendo cada vez más compleja la oferta exportable (con estrategias PAD), es el camino adecuado para aumentar las ventas al exterior $y$, por lo tanto, la cantidad de bienes y servicios que se producen con los recursos escasos (productividad) y la captura de porciones crecientes del mercado mundial (competitividad); en pocas palabras para impulsar el desarrollo económico nacional ${ }^{2}$.

Para convertir una nación en una organización altamente competitiva es necesario adoptar una perspectiva sistémica en la que, como en "Fuente Ovejuna: todas a una", las políticas de inserción en el mundo global (documento 2019, acuerdos comerciales, TLC's, tratados, etc.), las políticas macroeconómicas (tasa de cambio, devaluación, salarios, empleo, etc.), las políticas regionales de conformación de "clusters" $\mathrm{y}$ fortalecimiento de cadenas productivas y las micro económicas empresariales, estén orientadas sinérgicamente en la búsqueda de los objetivos comunes del desarrollo nacional. (Garay Luís Jorge, 2007) ${ }^{3}$.
A continuación se analizará con mayor detalle el contenido de la Política de Transformación Productiva y la estrategia operativa PAD que pueden impulsar los "clusters" de conocimiento o el Comité Universidad Empresa, en la búsqueda de una mayor competitividad y productividad.

Por ahora, no sobra recalcar que la conformación de "Clusters" de Conocimiento, es una herramienta y no un fin y que el objetivo básico es alcanzar mayores niveles de desarrollo económico para el país, aumentando para ello la competitividad y la productividad llevando los productos exportables del país hacia los Océanos Azules -poco competidos y de elevado margen- de los que hablan Chan Kim y Mauborgne, $2005^{4}$.

El "Cluster" del Conocimiento del País Vasco constituye uno de los ejemplos de asociaciones regionales exitosas que pueden señalar la ruta para construir en Colombia organizaciones similares. El objetivo general que se le definió a este "Cluster", fue el de "construir un espacio que impulse, permita y facilite la gestación de nuevos conceptos, ideas y prácticas con los que afrontar los importantes retos de los/as socios/ as del Cluster del Conocimiento, que se derivan de la economía globalizada y de la sociedad en red". Entre los socios del "Cluster" se encuentran las principales universidades de la región y numerosas empresas de diferentes tamaños.

Las acciones que se desarrollan alrededor del objetivo fijado representan, tal vez, uno de los

\footnotetext{
2 Los problemas relacionados con el bienestar, la responsabilidad social empresarial y la calidad de vida que deben producir los aumentos en competitividad y productividad son tema de otros documentos que está desarrollando la Universidad EAN.

3 Este es el planteamiento central sobre competitividad sistémica de la Ponencia de Garay L.J. en el Encuentro Internacional de Administración realizado en Cali en noviembre de 2007. (Garay L.J. 2007). Cabe anotar que el enfoque sistémico no es privilegio de la teoría del desarrollo económico y empresarial, sino que ha invadido todas las disciplinas científicas, incluidas las que antiguamente se denominaban ciencias duras.

3 Haussman recomienda y en ello coincidieron Stiglitz y Porter, «saltar al lado»; es decir, más que descubrir en Colombia nuevas ramas productivas como la aeroespacial u otras muy sofisticadas, es mejor trabajar en la innovación, la productividad y la competitividad de las ramas en las que ya tenemos avances significativos como en el «cluster» petroquímico - plástico de Cartagena.
} 
mejores ejemplos de la sinergia que puede generar una adecuada relación UniversidadEmpresa-Centros de Investigación en el camino hacia una mayor competitividad.

Además del ejemplo del "Cluster" del País Vasco, existe en Colombia un esfuerzo de similar importancia pero concentrado en una cadena específica de producción. Como lo señaló la prensa nacional, "el lunes 26 de noviembre, se inició en Cartagena la construcción del primer cluster de la industria del plástico. Un conglomerado que contará con diez nuevas plantas de igual número de empresas de plásticos en un lote de 200.000 metros cuadrados. La inversión inicial será de US\$150 millones". (El Espectador.com, 2007).

Este "Cluster" del Plástico recorrió un largo camino, pues como lo señala Carlos Alberto Garay (Director de ACOPLÁSTICOS), "antes que crear un cluster, había que pensar en tener una cadena productiva integrada". Este no era un proceso fácil, mucho menos cuando el sector reúne alrededor de quinientas empresas, que mueven dos mil establecimientos comerciales".

El primer paso, que demuestra la importancia del conocimiento en un proyecto como éste, fue la creación del Instituto de Capacitación e Investigación del Plástico y el Caucho -ICIPC, con sede en Medellín, que indagó sobre cuáles debían ser las prácticas para que la industria del plástico nacional tuviera la producción más eficiente posible y pudiera aprovechar el hecho de tener tan solo tres años de atraso en comparación con la industria internacional.

El gremio, que en rigor jugó el papel de un "cluster" del conocimiento, creó, al lado de la Universidad y los empresarios, el citado ICIPC; investigó las necesidades y brechas tecnológicas de las empresas relacionadas con la cadena; formó profesionales y PHd's en Colombia y en Alemania, en su mayoría especialistas en los procesos y productos relacionados con la cadena productiva; elaboró los documentos necesarios y realizó los trámites frente al estado superando todas las vicisitudes posibles, hasta construir hoy el "cluster" exportador que empieza a funcionar en Cartagena con miras al aprovechamiento inteligente de los TLC's que está firmando el país. Supera esta iniciativa los obstáculos existentes en cuanto a innovación con el respaldo de un centro de investigación de punta y en cuanto a localización situando el "cluster" en un puerto privilegiado para la exportación.

El caso empresarial de Acoplásticos, así como el del País Vasco, muestran, entonces, ejemplos de rutas claras y exitosas para imitar e impulsar en nuestro país. 


\section{LA AGREGACIÓN DE VALOR EN CONOCIMIENTO ÚTIL PARA PROCESOS, PRODUCTOS Y ORGANIZACIONES. UNA TAREA CENTRAL PARA LA TRANSFORMACIÓN PRODUCTIVA DE LA ECONOMÍA COLOMBIANA}

$\mathbf{P}$ mación productiva y como uno de los primeros elementos para la revisión de las directrices de los programas empresariales, el gobierno nacional partió de constatar el hecho de que "en los últimos años la posición relativa de competitividad de Colombia no ha mejorado" y que "el país perderá rápidamente la posibilidad de incorporarse al grupo de países de ingresos medios durante este siglo, si no se toman medidas inmediatas que aumenten la productividad laboral y del capital". Recalcó que si Colombia continúa aplicando el modelo de desarrollo actual y no introduce un cambio significativo "dentro de unos años pasará a formar parte del $26 \%$ de la población más pobre del planeta". (Plata L.G., 2007)5.

Es claro que los aumentos de productividad tienen estrecha relación con los aprendizajes y las mejoras derivadas de la ingeniería: rediseño de las líneas ("layout") de producción, adecuada introducción de maquinaria y equipos modernos, automatización y mejoras incrementales o radicales, cualitativas y cuantitativas en los procesos. En esta línea, la documentación y los procedimientos exigidos por la aplicación de las Normas ISO, contribuyen efectivamente a las mejoras de los procesos.

Pero también es cierto, que además de mejorar la técnica y la ingeniería de la producción, para ser más competitivos es necesario desarrollar productos innovadores que permitan generar diferenciales y salir de los océanos rojos internacionales altamente competidos donde tradicionalmente el país se ha movido, para navegar hacia los océanos azules en los que la innovación y la agregación de valor en conocimiento disminuyen significativamente la competencia y permiten obtener elevados márgenes de utilidad. $Y$ el sustento del movimiento hacia la innovación no es otro que la realización de procesos explícitos de agregación de valor en conocimiento a los procesos y productos; en una palabra, a toda la organización, incluidos los aspectos de gerencia y administración. Los "Clusters" de Conocimiento pueden ser una adecuada herramienta para dinamizar este objetivo.

Como lo señala buena parte de la literatura reciente sobre desarrollo económico y empresarial, es necesario que las organizaciones desarrollen procesos que les permitan recolectar datos, analizarlos y ordenarlos y con estos generar la información y el conocimiento útil para mejorar su competitividad y productividad.

Así, las mejoras en la planta y en el taller, tienen que acompañarse del desarrollo de procesos de gerencia y administración (gestión) del conocimiento de una manera transversal e integral en toda la organización y del desarrollo de los procesos necesarios para la agregación de valor y desarrollo de innovaciones, derivados de esa gestión. Esta puesta en marcha de los procesos de gestión del conocimiento, se ha convertido hoy, en el elemento determinante de la competitividad y la productividad de las organizaciones. (Hausmann Ricardo y Klinger Bailey, 2007).

\footnotetext{
5 Lógicamente en el siglo XXI cualquier estrategia de profundización manufacturera con agregación de valor en conocimiento para los productos, parte de un entorno global y de internacionalización con gran cantidad de tratados comerciales firmados o en proceso de firma.
} 
Para Hausmann (2007), hacer cada vez más compleja la oferta exportable de un país es uno de los caminos que conducen al desarrollo económico; este planteamiento tiene estrecha relación con la frase coloquial del Ministro de Comercio, Industria y Turismo durante su presentación en el Congreso de Acopi, que recuerda el proceso de Irlanda: "menos papa y más microelectrónica". Esta frase, que no por coloquial pierde su importancia, además de sintetizar la orientación de la política, resume la trascendental concepción según la cual el desarrollo de un país en el Siglo XXI, pasa por laAgregación de Valor en Conocimiento para los productos que se pretende exportar. No es que la papa sea un mal producto o que la microelectrónica sea el único camino para avanzar en la tarea del desarrollo; lo que simboliza la frase es que la simple siembra y la recolección de esos tubérculos y otros productos agrícolas sin valor agregado, puede ser realizada por numerosísimos productores y países y que, por lo tanto, si no se le agrega valor en conocimiento, si no se logra hacer un producto diferenciado más complejo, se estará nadando en un océano rojo de malos precios y elevadísima competencia ${ }^{6}$.

Desde la perspectiva del documento CONPES, el país "no solo debe hacer más internacionalización sino también más transformación productiva"; es decir, no solo expandir los mercados y las posibilidades de exportar cada vez más, sino que -siguiendo a Hausmanndebe aumentar la complejidad tecnológica de los bienes exportados, lo cual se puede medir entre otros indicadores que miden la proporción de las manufacturas dentro del total de las exportaciones.
Un dato fundamental que sustenta la orientación de la política hacia bienes manufacturados de mayor complejidad tecnológica, es el aportado por el estudio de los consultores Araujo Ibarra sobre las oportunidades en el TLC con los Estados Unidos.

\section{El 82\% de las importaciones de EEUU son BIENES}

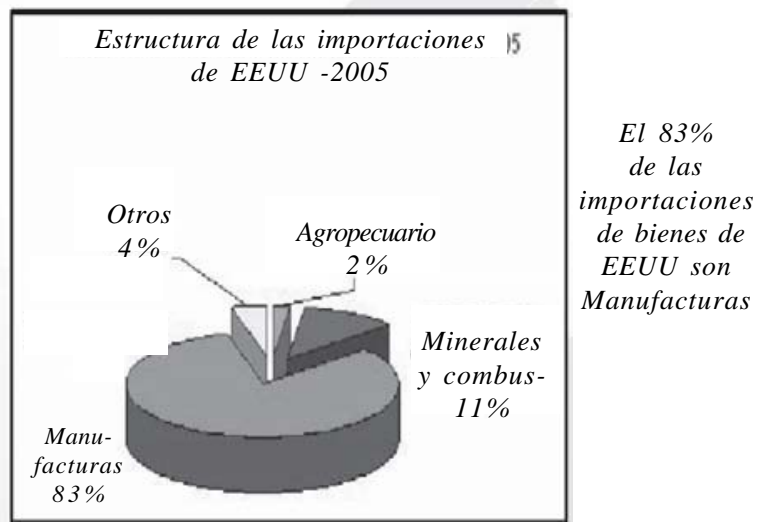

Como lo ilustra el gráfico de la consultora Araujo \& Ibarra, las alternativas de exportación hacia los Estados Unidos se concentran en los bienes manufacturados ya que en la composición de las importaciones el sector agropecuario tan solo representa el $2 \%$. La citada posición de Hausmann, Stiglitz y Porter, sobre aumentar la complejidad de la producción y de la oferta exportable, va en el mismo sentido y difícilmente un experto en temas de desarrollo económico podría recomendar un énfasis de la política de desarrollo empresarial en los bienes de tecnologías suaves, como los agrícolas, sin valor agregado. Adicionalmente, Paul Krugman (2008) señaló recientemente cómo la composición de las importaciones norteamericanas se ha redireccionado de un intenso comercio de manufacturas adquiridas

\footnotetext{
${ }^{6}$ Lo malo de los productos agrícolas sin valor agregado en conocimiento es que son inelásticos al ingreso y elásticos al precio; es decir, que si Colombia, por cualquier razón, aumenta unilateralmente el precio de uno de sus bienes agrícolas, sus ventas (demanda) caen fuertemente, mientras que el aumento del ingreso de la población de los países desarrollados no aumenta la demanda de este tipo de bienes. El ejemplo que un alumno de Maestría hizo es claro: si a un francés le aumentan su salario doce veces, su consumo de bananos por día se mantendrá en el mismo nivel de saturación alcanzado a mediados del Siglo XX. Este es un típico Océano Rojo.
} 
en los países desarrollados en la última mitad del siglo XX, hacia la adquisición de estas en los países en vías en desarrollo. "Hace poco cruzamos una vertiente importante, ahora Estados Unidos importa más productos manufacturados del tercer mundo que de otras economías avanzadas". (Krugman, 2008)

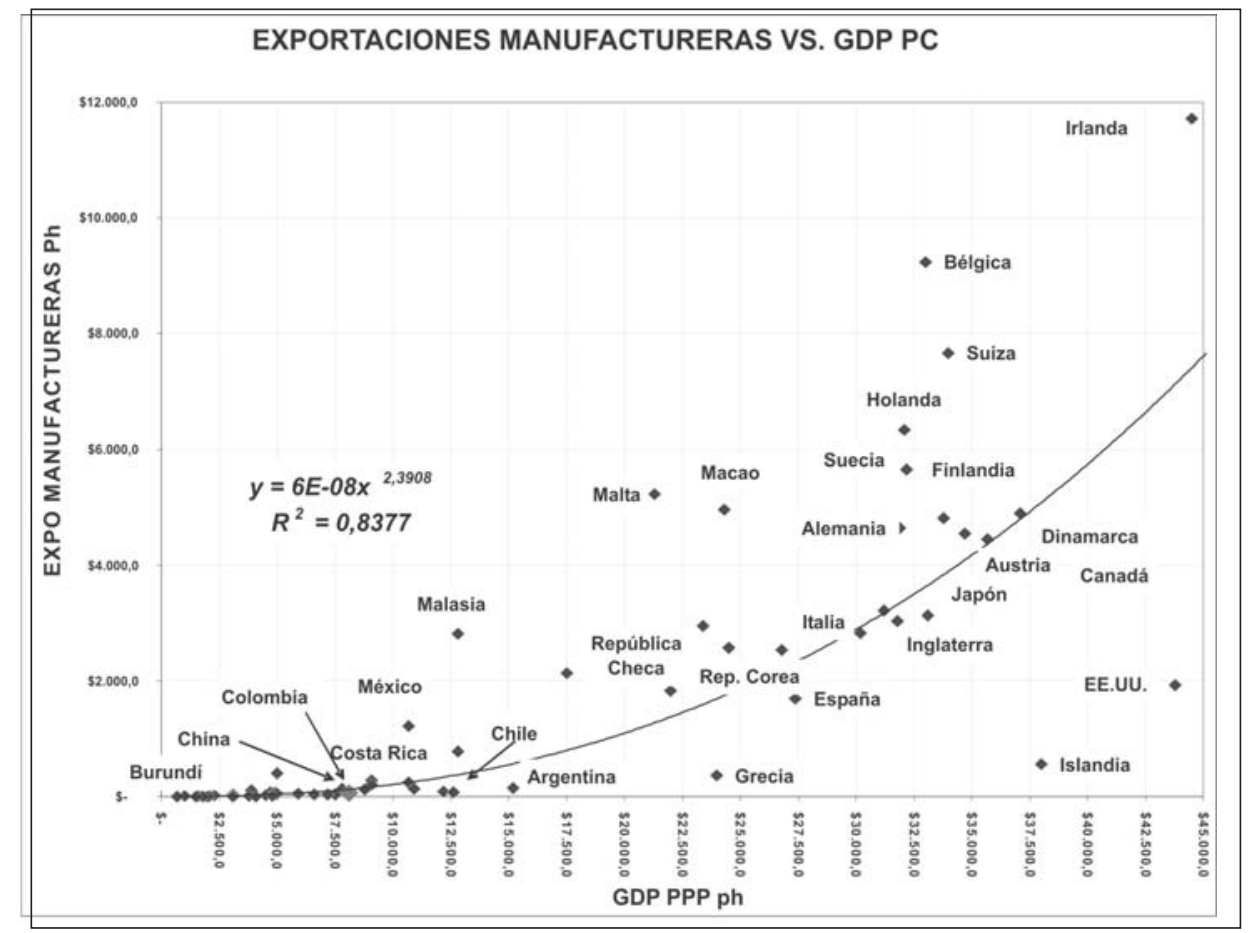

Si hubiera que reforzar la tesis del documento CONPES y de numerosos economistas postkeynesianos sobre las ventajas de profundizar la industrialización y aumentar la complejidad de la oferta exportable, el gráfico adjunto apoya la afirmación con la correlación positiva $\left(R^{2}=0,8377\right)$ entre la complejidad de las exportaciones (medidas aquí por las exportaciones manufactureras per cápita de los países) y el desarrollo económico, medido aquí por el PIB por habitante ponderado por el poder adquisitivo de la población (GDP-PPP Ph). El gráfico y el $\mathrm{R}^{2}$ hablan por sí solos, ilustrando los planteamientos de Hausmann y Stigltiz según los cuales entre más complejo es el aparato productivo de un país y, por lo tanto, sus exportaciones, mayor es su nivel de PIB por habitante. 


\section{La estrategia PAD. Herramienta NECESARIA PARA EL POSICIONAMIENTO INTERNACIONAL}

C

oincidiendo con estos planteamientos, la Universidad EAN ha insistido en varios artículos y documentos de investigación, sobre la necesidad de definir para el país la señalada estrategia PAD con sus tres elementos centrales: Posicionamiento de marca -P-, Agregación de Valor en conocimiento -A- $\mathrm{Y}$ Diferenciación del producto -D-. (Véase: Samir Kiuhan M., Matiz F.J., Pinzón G., Rodríguez R., Rojas A., 2006 y Nieto M., 2006) ${ }^{7}$.

El ejemplo del café es útil para describir el contenido de la estrategia PAD:

- Posicionamiento de marca-P-: la estrategia de posicionar la marca "Juan Valdez, Café de Colombia", mundialmente ha llevado al personaje del bigote y la mula, a ocupar el segundo nivel de recordación en el mundo, después del hombre de la peluca de la Avena Quaker. La excelente campaña para generar recordación sobre el café de Colombia, deberá extenderse a muchos otros productos colombianos de exportación.
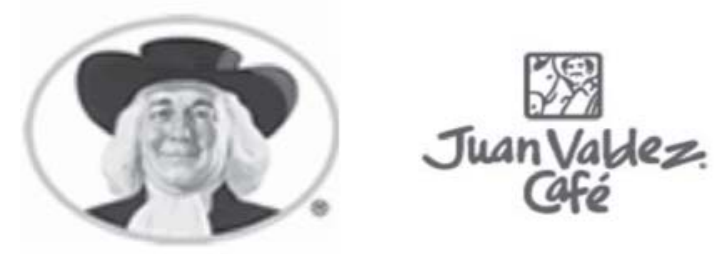

- Agregación de Valor en Conocimiento -A-: pero puede ser inútil generar recordación sobre un producto, si este no cumple las exigencias de calidad e innovación que exige el consumidor de los mercados de exportación. El continuar exportando café solamente en grano y en bultos, por bueno que sea este café, no generaría los diferenciales necesarios para salir del océano rojo donde navegan más de 116 países productores de todas las variedades de café en rama. Por eso, el haber pasado a agregarle valor al producto, mediante el desarrollo, en la fábrica de Chinchiná - Caldas, de procesos tecnológicos complejos que permiten liofilizar, producir café descafeinado y generar otras variedades, con agregación de valor en conocimiento al producto, es una excelente estrategia en línea con la campaña de posicionamiento de marca y que, además, ayuda a generar barreras a la entrada completándose la estrategia con la diferenciación del producto.

- Diferenciación de producto -D-: sobre la base del posicionamiento de la marca ("marketing") y de la Investigación y Desarrollo de nuevos productos (I\&D) se han ido diferenciando los cafés Gourmet, cafés especiales, Pods, etc. de Colombia, productos muy diferentes al café en bulto y que van generando la diferenciación que hacen del café colombiano, "el mejor café del mundo", un producto diferente al que producen los demás países cafeteros.

\footnotetext{
${ }^{7}$ La estrategia PAD se complementa bien con las propuestas de generación de océanos azules de Chan Kim y con el método de «las cinco fuerzas» de Michael Porter, dirigidas a identificar y penetrar mercados y a mejorar la competitividad. La amenaza de entrada de nuevos competidores se disminuye en proporción directa a la agregación de valor en conocimiento. Entre las principales barreras a la entrada en un mercado, se encuentran precisamente los componentes de conocimiento que se le agreguen a los productos objeto de la estrategia. En segundo lugar, la mejor forma de alejarse de los océanos rojos hipercompetidos de los «commodities» producibles por cualquier país, que Porter denomina como los mercados de extrema «rivalidad entre los competidores», es generando océanos azules a través de estrategias PAD. En tercer lugar, el poder de negociación de los compradores disminuye cuando se trata de productos PAD posicionados, pues adquirir bienes o servicios exclusivos con valores agregados y claramente diferenciados no es fácil. Finalmente, el PAD también disminuye por obvias razones la amenaza de ingreso de productos sustitutos y el poder de negociación de los proveedores.
} 
Con el PAD completo, el café colombiano Juan Valdez ha incrementado sus ventas significativamente y grandes cadenas del mundo lo están empezando a distribuir en sus diferentes variedades. La política planteada por el Ministro, está de acuerdo en que no es abandonar los bienes agrícolas con buena perspectiva, sino en que entre mayor sea la agregación de valor en conocimiento de estos productos, mayores serán sus posibilidades de generar buenas barreras a la entrada, un adecuado posicionamiento y una clara diferenciación.
Un elemento esencial para el éxito de un programa PAD es la conjunción de esfuerzos, conocimientos y recursos del Gobierno, la academia y los empresarios. La falta de programas sinergéticos como los que desarrollan los "Cluster" del Conocimiento impiden que los proyectos a veces gubernamentales, a veces académicos y a veces empresariales tengan un impacto de gran nivel.

\section{AdEMÁs DEL CAFÉ ¿EN QUÉ OTRAS RAMAS SE DEBE APLICAR LA TRANSFORMACIÓN PRODUCTIVA CON ESTRATEGIAS PAD?}

\section{$\mathbf{S}$} sectores de clase mundial, el ministro Plata destacó como ejemplos del Japón, en el que el acero, la metalmecánica, la electrónica profesional y de consumo, el automotor y las auto partes constituyen los sectores líderes. Otro caso señalado fue el de Irlanda, de gran interés por sus similitudes con Colombia en cuanto al desarrollo económico tardío y su prolongado conflicto interno ${ }^{8}$ y en el que los sectores destacados son el farmacéutico, los alimentos y bebidas, los servicios financieros y de educación. Finalmente, se recordó el caso de Corea del Sur, con los combustibles, la electrónica, las telecomunicaciones, los materiales básicos y la construcción. Recalcó el Ministro que estos países producen teniendo en mente la demanda internacional y que no pretenden competir únicamente con precios, sino fundamentalmente con valores agregados.

De los sectores destacados como de clase mundial, es clara la coincidencia con ramas colombianas que han demostrado su elevado potencial como son las de alimentos y bebidas (cárnicos, lácteos, hortofrutícola, oleaginosas, etc.), farmacéutica y medicamentos, automotriz, auto partes, servicios financiero y de educación, combustibles (bio) y construcción.

8 Irlanda se ha convertido en un referente y ejemplo de generación y consolidación de desarrollo económico sostenido en corto tiempo y es un caso conocido como el del Tigre Celta, relacionándolo con el de los conocidos Tigres Asiáticos. http://www.planea.org.co/ web/inputs/3Irlanda\%20SMontoya\%2010abril06.doc. El conflícto económico, adicionalmente, revistió en este país, aristas religiosas: «Protestants and Catholics have been fighting in Northern Ireland since the early 1900s and possibly even before that. While the two religious groups seem to be the main parties in the dispute, nationalism has played a very large role in the conflict between Northern Ireland and the Republic of Ireland. The dispute is caused mainly by the presence of the United Kingdom as a control group in Ireland, and the nationalists and the unionists have formed sides in the controversy». http://www.exampleessays.com/ viewpaper/74501.html. «El Ejército Republicano Irlandés (ERI) llevó a cabo durante más de treinta años una lucha armada para conseguir la retirada británica de Irlanda del Norte y la reunificación de la isla de Irlanda». http:// www.esmas.com/noticierostelevisa/investigaciones/463742.html. Un conflicto tan largo y complejo pudo superarse y hoy Irlanda es ejemplo de desarrollo económico. 
Lógicamente, la estrategia de agregación de valor o industrialización, no se dirige solamente a la rama manufacturera, sino que incluye el desarrollo de servicios modernos con valores agregados dentro de la concepción del "cluster", tales como los de la salud y la educación, vinculados al "cluster" del turismo en Bogotá Región y otras zonas.

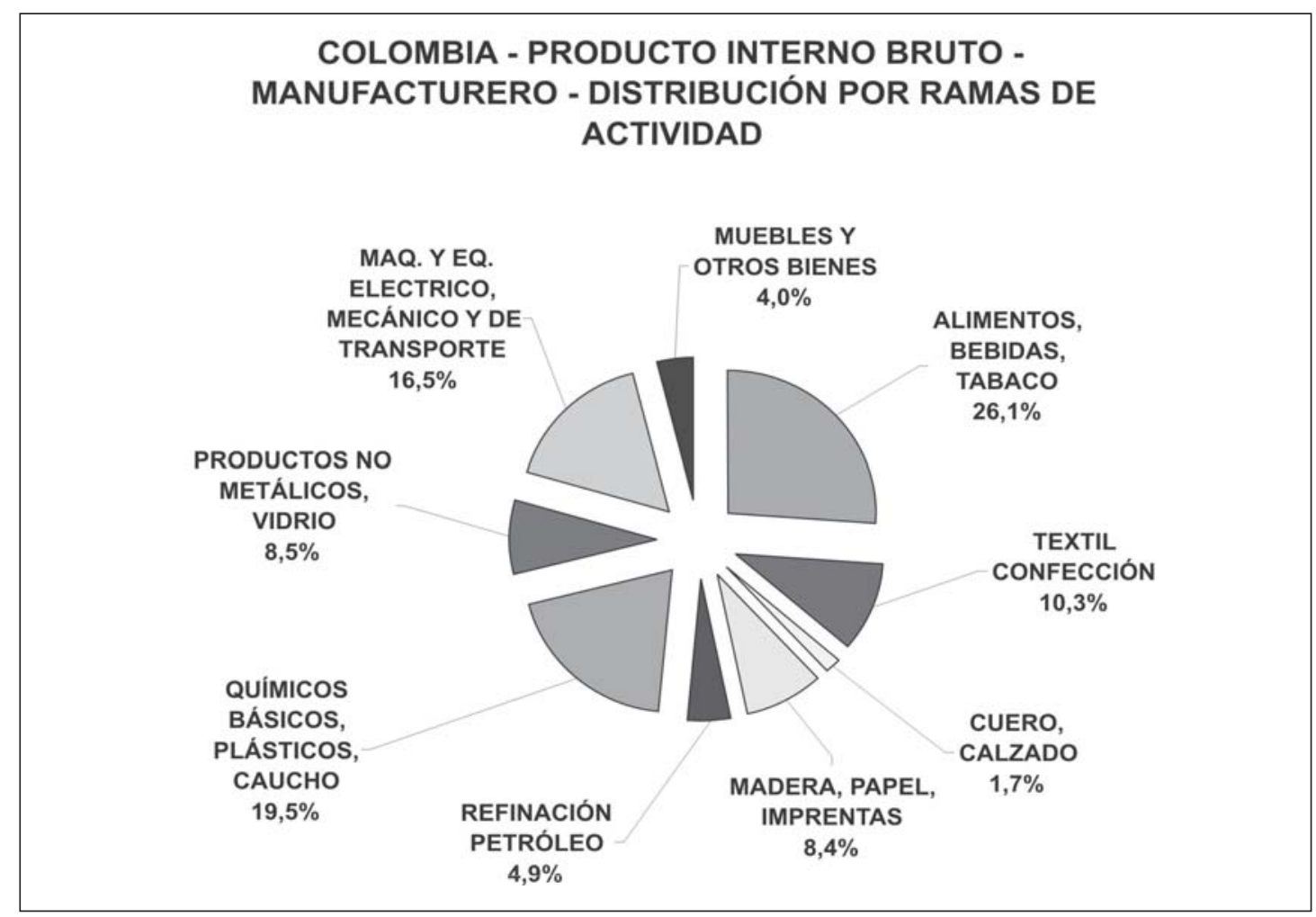

En términos más precisos, desde la década del 90, Michael Porter (Misión Mónitor) señaló los sectores y cadenas productivas que en su opinión deberían impulsarse alineando mediante programas explícitos al gobierno, los empresarios y la academia9. Estos sectores planteados hace ya casi 18 años por la Misión Mónitor, coinciden en términos generales con todos los estudios recientes relacionados con las cadenas destacas y susceptibles de ser el objeto de un ambicioso programa de competitividad sistémica.

\footnotetext{
9 http://www.camaramed.org.co/Documentos/docs/clusters/01informemonitorcolombia.doc. La Cámara de Comercio de Medellín recuerda que en 1992 y 1993, el Gobierno Colombiano y el sector Privado colombianos contrataron la firma Monitor dirigida por Michael Porter para identificar cómo Colombia, a largo plazo, podía ampliar y mejorar la competitividad. «El primer (estudio) se concentró en la industria petroquímica, mientras que el segundo analizó en detalle los sectores productores de flores, cueros, textiles, jugos de frutas, artes gráficas y metalmecánica. Adicionalmente, se adelantó un diagnóstico preliminar de la situación competitiva del sector turístico. Los resultados de estos estudios ofrecieron recomendaciones para crear la ventaja competitiva de Colombia, a nivel general, horizontal y sectorial». Así, desde hace ya casi 18 años, el país cuenta con recomendaciones sobre como aumentar la competitividad y como seleccionar sectores prioritarios para dicha estrategia. Se ha contratado a Porter varias veces para lo mismo, pero hasta hoy no se ha puesto en marcha ninguna de sus recomendaciones.
} 
El listado adjunto elaborado por el DNP, resume los sectores y cadenas cuyo desarrollo fue propuesto por las regiones para la Agenda Interna ${ }^{10}$. Recoge este listado los sectores de mayor desarrollo relativo coincidiendo con la estructura productiva en la que el país se especializó durante todo el siglo XX, lo cual se ilustra en el gráfico adjunto sobre la estructura del PIB manufacturero.

\section{Agenda Interna}

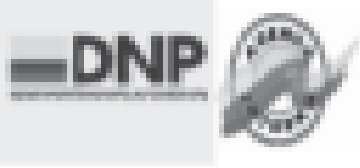

\section{Sectores participes en la Agenda Interna -Al-}

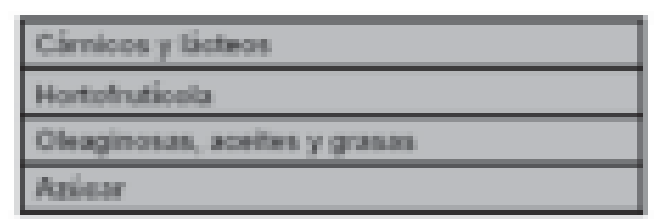

\begin{tabular}{|c|}
\hline 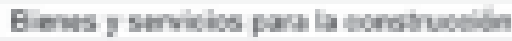 \\
\hline 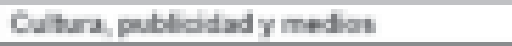 \\
\hline Ethmihin \\
\hline 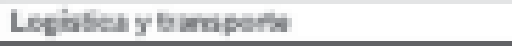 \\
\hline Anhy \\
\hline 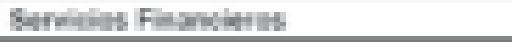 \\
\hline 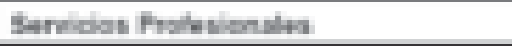 \\
\hline Buflain \\
\hline 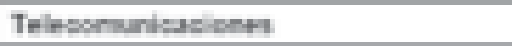 \\
\hline Tulnam \\
\hline
\end{tabular}

\begin{tabular}{|c|}
\hline 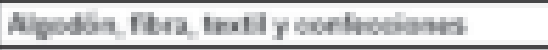 \\
\hline Ataneris \\
\hline 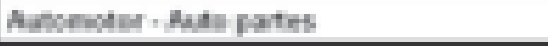 \\
\hline 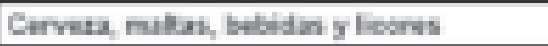 \\
\hline 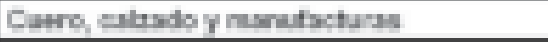 \\
\hline EFthen y alathola \\
\hline 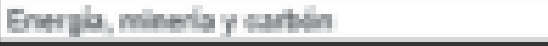 \\
\hline 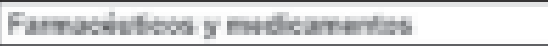 \\
\hline 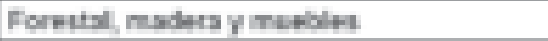 \\
\hline 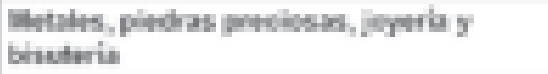 \\
\hline 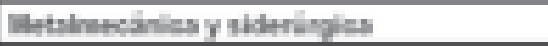 \\
\hline 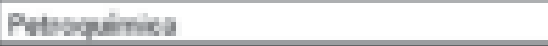 \\
\hline 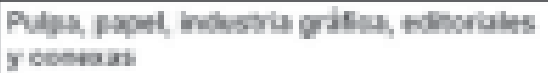 \\
\hline
\end{tabular}

animales vivos (ganado en pie), con un espectacular crecimiento durante los últimos cuatro años superior al $800 \%$ y la carne en canal y embutidos con un crecimiento, en el mismo período, de 145\%. (DIAN, 2007). Como agregado, la cadena productiva pecuaria, (ganado en pie, carne en canal y embutida y pieles y cueros) aumentó sus exportaciones de US\$ 100 millones en el año 2000 a casi US\$ 400 en el año 2006, mostrando una dinámica excelente. (DIAN, 2007).

\footnotetext{
${ }^{10}$ Departamento Nacional de Planeación. Agenda Interna para la Productividad y la Competitividad. Dimensión sectorial. Bogotá, junio 5 de 2007
} 
En cuanto a la rama hortofrutícola, las exportaciones de legumbres y hortalizas han tenido una revitalización a partir del 2004 con una tasa de crecimiento promedio anual cercana al $46 \%$. Con seguridad "clusters" con procesos PAD para esta cadena productiva, relacionada con las legumbres y las hortalizas, daría excelentes resultados para aumentar los volúmenes de exportación.

En Colombia, la cadena productora de bebidas y líquidos alcohólicos no está presentando la dinámica que experimenta la de los alimentos señalados. En efecto, mientras que durante los años 2000 y 2001 la tasa promedio de crecimiento de las exportaciones de bebidas se elevó al 38\%, en los últimos años (20032006) esta ha estado disminuyendo hasta llegar en 2006 a un crecimiento mínimo de tan solo el $2,3 \%$. Prueba este comportamiento la necesidad de agregar valor a los productos exportados a riesgo de perder los mercados internacionales ya penetrados. En este sentido, los ejemplos de Francia y Chile ilustran estrategias PAD exitosas basadas en el posicionamiento de sus marcas, en la aplicación de programas de innovación, tecnología y calidad en el proceso de producción y en el producto final así como la diferenciación de los productos con certificaciones de origen AOC ("Appellation d'Origine Contrôlé") y en el etiquetado para la distribución al cliente final. Este tipo de estrategia PAD también está siendo aplicado por los mexicanos en las exportaciones de Tequila, bebida que hace solo unos años era un licor exclusivamente popular y que hoy se exporta a los Estados Unidos en cifras crecientes $^{11}$. En Colombia, con excepción del café y, en alguna medida, los lácteos, no se observan estrategias PAD para otras bebidas de exportación.

En un segundo lugar de peso relativo dentro de la estructura productiva manufacturera del país, se han posicionado las cadenas productivas de los químicos básicos y la de los plásticos a las que ya se hizo referencia en este documento.

La cadena productiva de los químicos básicos se desarrolló abasteciendo el mercado interno y comenzó a exportar agroquímicos, fertilizantes, abonos, pesticidas y las resinas plásticas básicas como el Polietilentereftalato -PET- o el PVC. Los abonos agropecuarios constituyen una exportación menor que no supera los US\$20 millones en los últimos años y no muestra niveles importantes de crecimiento exportador. Los jabones industriales y de tocador presentan un mayor volumen con cifras de exportación que han superado los US $\$ 70$ millones anuales. (DIAN, 2007).

Pertenecen también a esta cadena los productos farmacéuticos que, aunque exportan una cifra más importante a las señaladas para los abonos y los jabones, cercana a los US\$300 millones, no han mostrado un crecimiento importante en los últimos años, presentando una tasa promedio anual de tan solo el 6,6\% entre el año 2001 y el 2006. (DIAN, 2007).

Por su parte, las manufacturas de plástico se consolidaron hasta el cliente final con productos de consumo (envases, empaques,

\footnotetext{
${ }^{11}$ La administración del Presidente Vicente Fox ha promovido el apoyo a la denominación de origen de la bebida «Tequila», por considerársele como un producto insignia de las cadenas productivas nacionales y debido a que el sector tequilero ha sido un ejemplo de competitividad nacional en el marco de los acuerdos comerciales suscritos por México». Gobierno de México, 2006. MÉXICO, D.F., 10 Enero 2007.- http://www.economia.gob.mx /work/normas/ Certificacion/Boletin_acuerdo_tequila.pdf. «Las exportaciones mexicanas de tequila aumentaron 19.65 por ciento en 2006 y alcanzaron una cifra sin precedentes de 140 millones de litros, informó hoy el Consejo Regulador del Tequila (CRT). El organismo calificó de «impresionante» este incremento, que estuvo acompañado por cifras récord en la producción total de tequila, que se situó en 242 millones de litros, un 15.68 por ciento más que en 2005". http:// www.planetaazul.com.mx/www/2007/01/10/exportaciones-de-tequila-crecieron-un-20-por-ciento-en-2006/
} 
juguetes, etc.) e insumos para otras ramas industriales y se están fortaleciendo hacia la exportación conformando "clusters" como el impulsado por Acoplásticos en Cartagena. El éxito de las estrategias desarrolladas por el "Cluster" del Plástico con alianzas estratégicas entre fabricantes de materias primas y productores de bienes finales para el consumidor, con relocalización y creación de nuevas plantas y con I\&D para la agregación de valor y la innovación, se refleja en el nivel de exportaciones de este tipo de productos que pasó de US\$391 millones en el $2000 \mathrm{a}$ casi el triple, US\$1.045 millones, en el 2006. (DIAN, 2007). Este es un caso, como ya se señaló, por analizar, para explorar la posibilidad de replicarlo en otras cadenas productivas.

El tercer lugar en importancia dentro de las ramas manufactureras lo ocupan los bienes de capital incluyendo el equipo de transporte. Estas ramas, fabricantes de maquinaria y equipo mecánico y eléctrico, han comenzado a exportar principalmente a los países del Pacto Andino y a Centroamérica y constituyen, tal vez, uno de los principales vectores de aprendizaje para la manufactura nacional pues sus procesos de producción tienen amplias exigencias hacia la ingeniería mecánica y eléctrica, aprendizajes que posteriormente pueden aplicarse a otras ramas de producción. El hecho de que las exportaciones de maquinaria y equipos mecánicos hayan superado los US $\$ 330$ millones en el 2006 y la maquinaria y equipo eléctrico los US\$ 365 millones triplicando cada una de estas cadenas productivas sus niveles, comparados con el año 2000, confirma la hipótesis de que la agregación de valor y la consecuente complejidad de los productos, les permite posicionarse efectivamente en el mercado internacional. En este capítulo, al lado del ensamble de automotores, se ha desarrollado una producción de auto partes que, igualmente, ha comenzado a constituir un renglón importante para la exportación.
La cadena algodón, textil, confección (10,3\% del PIB manufacturero sin contabilizar la producción de algodón) constituye el cuarto renglón de importancia en la producción manufacturera. Aquí, también, sin programas integrados del tipo PAD propuesto, los empresarios han encontrado nichos especializados para la exportación, tales como la ropa interior femenina.

Desde hace años, al igual que los textiles y las confecciones, el sector de la marroquinería, el calzado y el cuero se ha caracterizado como un sector con elevadas posibilidades exportadoras. Sin embargo, los esfuerzos de los empresarios para adecuar su oferta a los mercados internacionales buscando los nichos intermedios que los alejen de los productos de gran volumen producidos por la China, terminan siendo esfuerzos aislados, con escasos recursos financieros y sin apoyo gubernamental adecuado.

Durante los últimos años en los que se ha generado un auge sin precedentes en el sector de la construcción, la industria manufacturera relacionada, tal como la del vidrio, el aluminio, el cemento, los muebles de madera y metálicos para baños y cocinas, los eléctricos para el hogar, las alfombras, pinturas, lacas y barnices, etc., ha ido constituyendo, sin que medie ninguna política de apoyo y promoción ni estatal ni privada, un "cluster" que ha iniciado con relativo éxito sus exportaciones. (Nieto M. 2006). Un impulso decidido para la innovación, el desarrollo tecnológico y la modernización de las organizaciones de esta cadena productiva puede tener un gran impacto en las exportaciones que ya han demostrado una buena dinámica.

El sector papelero y de impresión es otro sector que ha demostrado vocación exportadora frente al cual es necesario generar un "Cluster" de Conocimiento que permita desarrollar los programas y proyectos que garanticen un 
incremento sustantivo en el volumen exportador. Existen ya semillas para la construcción de este tipo de organizaciones como son el gremio Andigraf y el Centro de Investigaciones Cigraf. Al lado de la academia, estas organizaciones empresariales han comenzado a realizar acciones de formación, modernización e investigación que con el apoyo del gobierno pueden llegar a generar impactos significativos en las empresas.
En el diseño de estos "Cluster" de conocimiento y de sus programas y proyectos los gremios de la producción, sus centros de investigación y las Universidades pueden jugar un papel muy importante, siempre y cuando el gobierno nacional logre jugar el papel de coordinador $y$ promotor. Las convocatorias de FOMIPyME son, por ejemplo, una herramienta que puede ser muy útil para alcanzar estos objetivos de productividad y competitividad.

\section{IMPULSAR EL DESARROLLO EMPRESARIAL UTILIZANDO LA INVERSIÓN EXTRANJERA DIRECTA}

\begin{abstract}
A propuestas, el documento CONPES señala que para dar impulso a la estrategia hacia la agregación de valor y el fomento de las exportaciones de mayor complejidad, se utilizará como herramienta adicional la Inversión Extranjera Directa -IED- en sectores de clase mundial ${ }^{12}$. En este contexto, se buscará que la PyME se encadene a las firmas multinacionales que realicen IED en el país, mediante modalidades de subcontratación, encadenamientos productivos o "clusters", generando desarrollos empresariales.
\end{abstract}

Entre las herramientas de apoyo a la política de promoción a la inversión extranjera directa cabe destacar las siguientes:
- "Las Zonas Francas Uniempresariales: éstas permitirán, sin exigencias específicas de ubicación geográfica, obtener privilegios tributarios que podrían significar una disminución del 15\% al 30\% y exenciones del IVA.

- Contratos de estabilidad jurídica de mediano y largo plazo: frente al tema de la inestabilidad jurídica para las inversiones extranjeras, el Ministerio está planteando la posibilidad de firmar contratos de estabilidad jurídica fijando reglas del juego de mediano y largo plazo. De esta forma, independientemente de que en el país cambien algunos de los parámetros del entorno macroeconómico de libre fijación de los gobiernos, el contrato obligaría a mantener aquellos que fueron pactados a la firma de este tipo de contrato.

\footnotetext{
12 El «aumento de la inversión extranjera directa -IED- a través de sectores de clase mundial» es una de las tres estrategias planteadas por el Ministro. Sobre el tema de la Inversión Extranjera Directa -IED- y su impacto en el desarrollo nacional, en alianza con el Consejo de Empresas Americanas -CEA- la Universidad EAN finalizó un proyecto de investigación con el análisis de los determinantes de la localización y de las cifras más recientes para la caracterización de esta importante variable. (Véase Nieto M, Ortiz W., 2007)
} 
Estos incentivos que se otorgarán a las firmas extranjeras que inviertan montos superiores a los US\$ 500 millones y generen un volumen importante de empleos, pueden generar la diferencia en el momento de tomar la decisión de invertir al comparar a Colombia con economías de similares condiciones de ubicación geográfica. (Nieto M. y Ortiz W., 2007)

Sobre la posibilidad de generar este tipo de encadenamientos con inversionistas extranjeros, se señala como ejemplo el positivo impacto de la firma Intel en Costa Rica. De acuerdo con los análisis recientes sobre el impacto de esta experiencia "la instalación de la multinacional Intel hace 10 años en Costa Rica ayudó al país a ubicarse como destino para la inversión extranjera directa (IED); pero además impactó su economía en formas menos tangibles.... El análisis realizado por el ex ministro de Comercio Exterior, Alberto Trejos y el economista Félix Delgado, de la consultora Consejeros Económicos y Financieros (CEFSA), confirmó con datos concretos lo que muchos sospechaban desde que Intel anunció el 13 de noviembre de 1996 que abriría una planta en Costa Rica: la decisión cambiaría el rostro del país". (El Diario de Hoy, 2006).

Según lo afirman estos autores, Intel representa cerca del seis por ciento del PIB, algo muy notable por tratarse de una sola empresa en tanto que en el área de inversión directa, la firma ha inyectado a la economía costarricense unos 90 millones de dólares por año, lo que de 1997 al 2005 fue el $25 \%$ de la IED total. Desde la llegada de esta multinacional, la IED pasó de $\$ 300$ millones anuales a poco más de $\$ 600$ millones de dólares por año". (El Diario de Hoy, 2006).

Un aspecto que garantiza el impacto positivo de la inversión extranjera es que ésta sea directa -IED-; es decir, que se realice en el aparato productivo y de servicios y no en papeles de especulación para capturar tasas elevadas de interés como capitales golondrina. Como lo señala Garnier, (2000) para Costa Rica las exportaciones de la multinacional generan un efecto positivo sobre la balanza comercial, aportando divisas frescas en un país que las requiere para financiar su crecimiento y sus importaciones. Después de la llegada de Intel, "hay mucho menor presión sobre el mercado financiero del que habría si una inversión de esa magnitud hubiera tenido que financiarse con ahorro interno". (Garnier Leonardo, 2000). De otro lado, aunque este tipo de firmas pague salarios inferiores a los que paga en su país de origen, es claro que el nivel salarial de la empresa en los países emergentes es superior al que generalmente pagan las empresas locales. El diferencial salarial a favor de la Inversión Extranjera Directa, implica en el caso de Intel que "la mano de obra costarricense empieza a competir por mejores (y no simplemente por más) empleos, empieza a integrarse a una carrera ascendente de movilidad social. La mano de obra que se mantendrá barata y empobrecedora, es la que no logre abandonar las actividades productivas de menor productividad, donde sólo importa el costo y no la capacidad de los trabajadores. No es ese el caso de estas nuevas inversiones". (Garnier Leonardo, 2000, EFECOM, 2007).

Ahora bien, no bastará con atraer varias firmas internacionales de sectores de clase mundial sino se logran encadenamientos positivos con las pequeñas y medianas empresas colombianas. Intel inició sus operaciones en Costa Rica con una planta de ensamblaje y prueba de microprocesadores, pero actualmente se diseñan microchips y circuitos electrónicos, se realizan investigaciones y se prestan servicios financieros y contables para toda la corporación. (EFECOM, 2007). 
La transferencia de tecnología es una posibilidad contractual que puede negociarse y lograr que firmas locales asimilen y adapten algunos de los conocimientos que se encuentran implícitos en los procesos de producción, en la fabricación de partes y piezas y en los productos finales. Al lado de la estrategia de promoción de la IED, puede generarse una estrategia complementaria de transferencia de tecnología desde las firmas multinacionales hacia las PyMEs que formen parte de la cadena productiva. Sin habérselo propuesto contractualmente, la ingeniería costarricense ha comenzado a beneficiarse de la IED de Intel.

\section{LA POLÍTICA DE LA TRANSFORMACIÓN PRODUCTIVA REITERA LA IMPORTANCIA ESTRATÉGICA DE LA MIPYME PARA EL DESARROLLO ECONÓMICO}

("El Mincomercio será el Ministerio de las MIPyMES")13.

El Ministro Plata señaló varias veces como un ejemplo interesante, el modelo económico de Taiwán, país que utilizó el segmento PyME de la manufactura para alcanzar elevados niveles de desarrollo. Mostró con varias cifras comparativas como mientras los países del sudeste asiático y de otros continentes han elevado sus cifras de productividad, competitividad, ingreso percápita y otros indicadores de desarrollo a través de procesos de consolidación industrial, Colombia se mantiene estático sin avances notorios en ningún campo de la producción.

Participación de establecimientos y personal ocupado por tamaños (\%)

\section{A. Establecimientos}

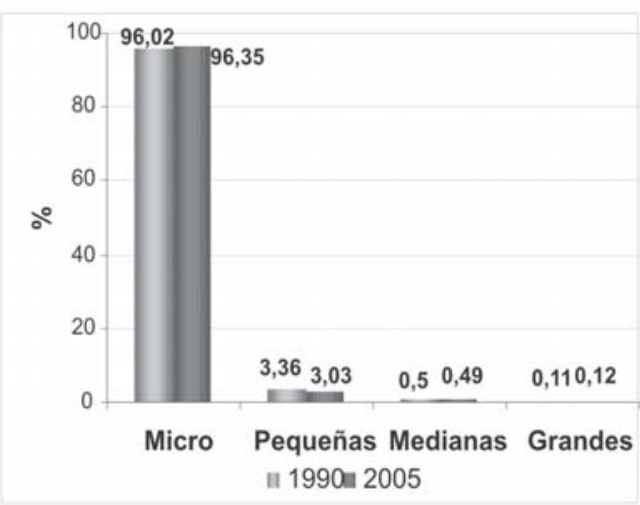

B. Personal Ocupado

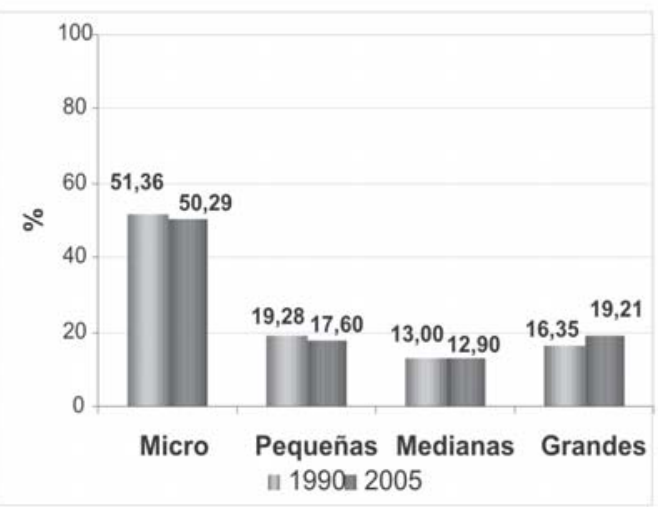

Fuente: Censo Económico 1990 y 2005. Cálculos

CDM y DNP-DDE

\footnotetext{
${ }^{13}$ Afirmación del Ministro, dr. L.G.Plata en su ponencia.
} 
Contrastó el Ministro los casos de países con modelos de desarrollo agrario frente a otros como Taiwán con un modelo de desarrollo manufacturero. Se pueden encontrar países con dotaciones de recursos naturales escasos y similares a las de Taiwán, país que se desarrolló a través de un proceso manufacturero de agregación de valor llegando en 2006 a un PIB per cápita (PPP, $\mathrm{ClA}^{14}$ ) de US\$ $\$ 29,500$ (2006 est.) y otras que han mantenido su vocación agraria y que hoy presentan niveles de atraso económico significativo con PIB per cápita (PPP) inferiores a los US $\$ 4,000$ (2006 est.). Como punto de referencia cabe señalar que en PIB per cápita (PPP) Colombia alcanza hoy los US\$ 8,600 (2006 est.).

Como lo señaló el Ministro en su presentación (Plata L.G., 2007) ${ }^{15}$ y también lo ilustra el documento CONPES, se confirman los datos según los cuales la MIPyME representa la casi totalidad de los establecimientos y del empleo generado en el país, en tanto que la gran empresa tan solo constituye el $0,12 \%$ de los establecimientos y el $19,2 \%$ del personal ocupado ${ }^{16}$.

\section{Desarrollar La CUltura asociativa en LAS EMPRESAS PYME}

$\mathbf{F}$ a otro punto de trascendental importancia señalado por el documento CONPES y es el tema de la asociatividad empresarial. Desde el 2006, la Universidad EAN, entendiendo la trascendencia de esta estrategia empresarial, desarrolló una línea de investigación sobre el tema que condujo a una primera publicación de un libro el cual realiza una aproximación conceptual a los factores determinantes de la asociatividad (competencia, teoría de juegos, confianza y conflicto) y analiza algunas experiencias asociativas en el país, como la
Alianza TEAM, Corinca, ASESEL y algunas de las experiencias PRODES. (Castellanos, 2007) En la actualidad se están desarrollando los términos de referencia para continuar investigando sobre el desarrollo de herramientas prácticas para promover y facilitar la asociatividad empresarial.

Queda claro que la estrategia del Gobierno Nacional se centrará en promover la fabricación de productos con valor agregado en conocimiento, en utilizar la Inversión Extranjera Directa como vector de desarrollo y en

\footnotetext{
${ }_{14}$ «In the Economy category, GDP dollar estimates for countries are reported both on an official exchange rate (OER) and a Purchasing Power Parity (PPP) basis. The PPP method involves the use of standardized international dollar price weights, which are applied to the quantities of final goods and services produced in a given economy. The data derived from the PPP method probably provide the best available starting point for comparisons of economic strength and well-being between countries».

${ }^{15}$ Plata Luís Guillermo, 2007: Noticia de prensa.

${ }^{16}$ Una argumentación sobre el eje de la política centrado en las PyMES y las cifras sobre la trascendencia de este segmento en empleo y establecimientos, puede leerse en el primer trabajo del Observatorio Económico de las PyMES. Véase: Observatorio Económico para la PyME Colombiana EAN-ACOPI-CINSET-DANE, 2005.
} 
promover el encadenamiento de los segmentos MIPyME a estos vectores, entendiendo que para el desarrollo empresarial, así como para la lucha contra la pobreza y el desempleo, este tipo de organizaciones MIPyME constituyen una herramienta fundamental.

Dentro de los programas que se desarrollarán en este contexto de políticas, la conformación de "Clusters" de Conocimiento, en los que el Gobierno, las empresas y las universidades finalmente se consoliden como unidades productoras de datos, información y conocimiento útil para el desarrollo empresarial y para la consolidación de organizaciones innovadoras, más productivas y eficientes, seguramente ocuparán una parte central de la tarea conjunta para el trípode: GobiernoUniversidad-Empresa. Reiteremos que producir conocimiento no es un fin sino un medio y que el objetivo final de asimilar, adaptar y generar conocimiento no es otro que el de aumentar la productividad y la competitividad de las organizaciones productivas y de servicios, condición esta necesaria para alcanzar el desarrollo económico nacional y el bienestar de la población.

\section{BIBLIOGRAFÍA}

Araujo \& Ibarra consultores, 2006: "500 nuevos productos y servicios con potencial exportador desde Colombia al mercado de los Estados Unidos". http://www.araujoibarra.com/ Productos\%20USA/500\%20productos\%20potenciales\%20ESTADO\%20A\%20JULIO.pdf.

BELLY, Pablo L., 2002: "Conocimiento y Sociedad. Nuevas reglas económicas, nueva economía". http://www.bellykm. com/.

CASTELLANOS, Juan Gonzalo, compilador; LOPEZ, Luis Guillermo, ORTIZ, Carolina y TORO, Jacqueline; 2007: "Asociatividad Empresarial, Perspectivas, Valoración del potencial de la empresa". Universidad EAN, Bogotá, Colombia.

CIA, 2007: www.cia.gov: https://www.cia.gov/library/publications/the-world-fact book/docs/ notesanddefs.html\#2004.

CHAN KIM, W. y MAUBORGNE, Renée, 2005 : "Blue Ocean Strategy: How to Create Uncontested Market Space and Make Competition Irrelevant.". 3 de Febrero 2005, Editorial: Harvard Business School Press. 256. ISBN: 1591396190.

Consejo de Empresas Americanas-CEA-, Universidad Ean, 2007: "La inversión extranjera Directa en Colombia". Documento preliminar. Bogotá, Colombia.

DIAN, 2007: base de datos sobre exportaciones. Sistema de información. www.dian.gov.co. 
El Diario de Hoy, 2006: "Tecnología. La firma electrónica INTEL permitió atraer empresas de mayor valor agregado". 7 de octubre de 2006.

EFECOM, 2007: http://www.eleconomista.es/empresasfinanzas/noticias/81837/ 01/07/ Intelsupone-el49-por-ciento-del-PIB-de-Costa-Rica.html.

Empuje, 2007: "Gracias a Intel aumentó la inversión extranjera". San José, El Diario de Hoy, negocios@elsalvador.com. http://www.el salvador.com/noticias/2006/10/07/.

El Espectador.com, 2007: Semanario del 24 de noviembre al 1 de diciembre de 2007.

GARAY, Luis Jorge, 2007: "Ponencia al Encuentro Internacional de Administración" Univalle, Cali Noviembre. Documento ASCOLFA en proceso de publicación.

GARNIER, Leonardo, 2000: "El impacto de Intel en Costa Rica". Diario "El Financiero", Febrero. San José, Costa Rica. http://www.leonardogarnier.com/ index.php?option=com_content\&task=view\&id=324\&ltemid=49. Ministro de Edu-cación de Costa Rica.

Gobierno de México, Dirección General de Comunicación Social, 2006: "Comu-nicado de prensa Núm. 002 /06 México, DF, 17 de enero". Firman México y Estados Unidos acuerdo para garantizar la autenticidad del tequila exportado a granel.

HAUSSMAN, Ricardo y KLINGER, Bailey, 2007: "Achieving Export-Led Growth in Colombia" Quantum Advisory Group. Documento preparado para la Presidencia de la República.

KRUGMAN, Paul, 2008: "El problema con el comercio". Semanario El Espectador, 6 al 12 de enero. Bogotá, Colombia.

KIUHAN, Miguel Samir, MATIZ, Francisco Javier, PINZÓN, Gabriel, RODRÍGUEZ, Román, ROJAS, Alvaro, 2006: "El café de Colombia. Un modelo de diferenciación de producto, posicionamiento de marca y valor agregado. Revista EAN No.56, Enero-Abril.

NIETO POTES,, Mauricio, 2006: "Agenda de competitividad, emprendimiento y creación de empresas. La coyuntura actual". Revista EAN, Número 57, Mayo-Agosto. Bogotá, Colombia.

NIETO POTES, Mauricio y ORTIZ ROJAS, Willington, 2007: "La inversión extranjera directa en Colombia". Investigación del Grupo Entorno Económico Universidad EAN, en asociación con el Consejo de empresas Americanas -CEA-. Bogotá, Diciembre 2007, documento en proceso de impresión.

Observatorio Económico para la PyME Colombiana EAN-ACOPI-CINSET-DANE, 2005: "Las pequeñas y medianas empresas en Colombia. 1992-2001. PyMES de la crisis al resurgimiento. Editorial DANE, Bogotá Colombia. 
PORTER, Michael, 2007: Reportaje concedido al diario El Tiempo. "Colombia es una estrella". Septiembre.

PLATA, Luís Guillermo, 2007: "Transformación Productiva. La estrategia para el Desarrollo Empresarial". Ministro de Comercio, Industria y Turismo. Presentación de la Política Gubernamental para el desarrollo empresarial consignada en el Documento CONPES No.3484, durante el 54 Congreso Nacional de la PyME - ACOPI, Agosto 23 de 2007.

2007: Noticia de prensa: "Fortalecimiento de PyMES busca documento CONPES": http://www.mincomercio.gov.co/eContent/NewsDetail.asp? ID =5932\&IDCompany.

PLAZ LANDAETA, Reinaldo, GONZÁLEZ AURE Néstor, 2004: "La gestión del conocimiento organizativo. Dinámicas de agregación de valor en la organización". Universidad Autónoma de Madrid http://www.mityc.es/NR/rdonlyres/8D3C8E36-AB60-4795-AF82-A254A874109C /0/ 05_ReinaldoPlaz357.pdf.

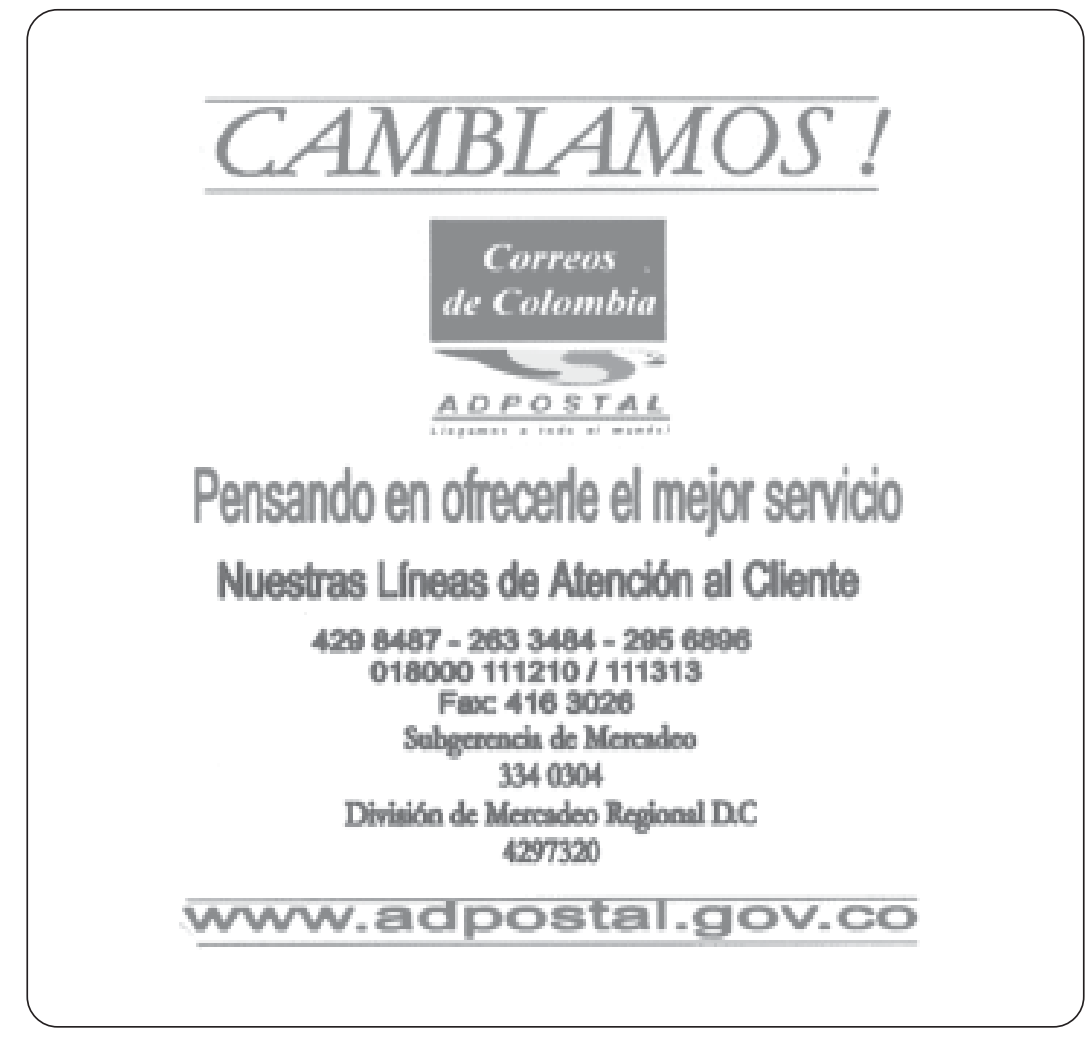


